\title{
The Efficacy of Progressive Muscular Relaxation Upon Nurses Sleep Quality
}

\author{
Mohammadreza Zarbakhsh ${ }^{1 *}$, Laleh Sayed Raisi ${ }^{1}$ \\ 'Department of Psychology, Tonekabon Branch, Islamic Azad University, Tonekabon, Iran
}

\begin{abstract}
Background: Nurses suffer from sleep disorders. Sleep disorders will lead to listlessness and distractibility, and interfere with people's normal working state. Effective methods upon nurses sleep quality should identify. The purpose of this study was determining the efficacy of progressive muscular relaxation (PMR) upon nurses sleeping quality.

Methods: The current research was an experimental study with pre-test and post-test design with the control group. The statistical population consisted of all nurses in Imam Sajad hospital in Ramsar $2017(\mathrm{~N}=120)$. In this way, 40 nurses who were in the test of the quality of sleep score above five were randomly selected and randomly divided into two groups. For data gathering, Pittsburgh sleeps quality questionnaire and PMR instruction used. It was used multivariate covariance analysis (MANCOVA) to analysis data by SPSS-22.

Results: The findings of this study showed that PMR instruction is useful for nurses' sleep quality. Also, there is a significant difference between experimental and control groups after the intervention, so that the mean scores of the experimental group were improved significantly compared to the control group $(P<0.0001)$.

Conclusion: According to results, PMR instruction can improve the sleep quality and other variables related to sleep problems of nurses. Therefore, it can be used in nursing programs to improve their sleep quality.

Keywords: Progressive muscular relaxation; Sleep quality; Nurses.
\end{abstract}

*Correspondence to

Mohammadreza Zarbakhsh, Assistant Professor, Department of Psychology, Tonekabon Branch, Islamic Azad University, Tonekabon, Iran Email: rzarbakhsh@yahoo.com

Published online 20 Decembe 2018

Citation: Zarbakhsh M, Sayed Raisi L. The efficacy of progressive muscular relaxation upon nurses sleep quality. Int Clin Neurosci J. 2018;5(4):164-168. doi:10.15171/icnj.2018.29.

\section{Introduction}

Sleep is one of the most important biological cycles that play a crucial role in restoring the physical and mental forces of individuals and is affected by the physiological function, brightness and darkness, work schedule and other activities (1). Nursing is one of the occupations involved in the work-shift and sleep disorders caused by it. This problem effects on body and mind and results in problems such as digestive disorders, cardiac problems, neurological exhaustions, decentralization, abnormal behavior, hallucination, affective maladjustment, and aggression. Sleep disorders of nurses that affect not only their health but also the health of patients under their supervision (2). Many of them may suffer from chronic pains and problems that affect their quality of life $(3,4)$. Therefore, sleep problems among nurses are important to take into consideration. Nurses with rotation in work shifting and nightly job have problems in their sleep. They also need to keep an all-night vigil, and such working mode makes their sleep time irregular. Nurses' sleep disorders not only influence their health but also affect the nursing quality and even the patients' psychological health and treatment process (5). Rotation in working shifts causes a decrease in the quality and quantity of sleep and the occurrence of drowsiness during the day (6).

Sleep disorders of the nursing job are important as follow: First, sleep disorders can endanger the health and safety of patients and nurses. Second, this occupation has several risk factors for a sleep disorder. Some factors such as work shift, deprivation from sleep, anxiety, and depression are important in this disorder (7). Sleep functions investigated in a variety of ways, most researchers concluded that sleep has equilibrium and restore function and it is imperative in regulating temperature and energy. Although the exact functions of sleep are not yet clear, its existence is essential for survival, because sleep deprivation leads to severe physical and cognitive destruction and finally death (8). In the Chien et al research on 156 female nurses in Tayvan by PSQI questionnaire indicated that $75.8 \%$ had PSQI $>5$ and $39.8 \%$ showed sleep disorder in mental scale (9). Also, Razmpa et al in 2009 investigated sleep disorders and its effective factors on 190 nurses at the Imam Khomeini hospital of Tehran University of Medical Sciences. The result showed that the prevalence of sleep

(C) 2018 The Author(s). This is an open access article distributed under the terms of the Creative Commons Attribution License (http:// creativecommons.org/licenses/by/4.0/), which permits unrestricted use, distribution, and reproduction in any medium, provided the original work is properly cited. 
disorder, insomnia, hypersomnia, respiratory blocking syndrome, and narcolepsy were $83.8 \%, 81.5 \%, 33.1 \%$, $12.1 \%$ and $3.7 \%$ respectively (7).

Different methods are used to treatment of insomnia, including the use of sedative or hypnotic drugs that treat short-term insomnia. Also, studies have suggested the use of cognitive-behavioral therapies to improve the quality and quantity of sleep in early insomnia (10). Primary methods of cognitive-behavioral therapies include relaxation training, stimulus controlling, sleep limitation and healthy sleep (11).

Progressive muscular relaxation (PMR) has been designed to reduce tension and anxiety (12). The purpose of this technique, create awareness tension and muscles relaxing (13). In the early 1930s, Jacobson showed that the efficacy of the PMR in reducing symptoms of arousal. During the second half of the 21 century, several types of relaxation therapy have known which derived from the early Jacobson observations and have been widely used to treat the symptoms of anxiety disorders. Cognitive and physiological excitement, concerned about the bed, and sleep-related anxiety are the most apparent symptoms of persistent insomnia. Relaxation techniques are the first behavioral therapy methods used for sleep disorders (14). According to research on 39 hemodialysis patients of Shahid Beheshti hospital in 2010, the results showed that PMR on sleep quality has a positive and significant effect on patients sleep quality (15). Therefore, according to issues as mentioned earlier, the importance of this subject and lack of studies in Iran about this subject, this study was executed with the aim of determining the efficacy of PMR on nurses sleep quality.

\section{Methods}

The current research was an experimental study with pre-test and post-test design with the control group. The statistical population consisted of all nurses in Imam Sajad hospital in Ramsar $2017(\mathrm{~N}=120)$. In this way, 40 nurses who scored above 5 in the sleep quality questionnaire randomly selected with simple random sampling and randomly divided into 2 groups (20 individuals per group). Subjects in the experimental group assigned with simple random sampling in 5 groups with each group including 4 persons (this done in order to accurately implement and reduce the lack of participation of subjects due to the type of occupation in educational sessions). In the pre-test, Pittsburgh sleep quality index administered to all study groups. Finally, each group (4 persons) participated in instructional sessions consist of 6 sessions, 30 minutes twice a week. After completing the PMR course, they performed daily training twice a day for 20 minutes each day for 6 weeks. Finally, at the end of the ninth week ( 3 weeks consist of direct instruction and 6 weeks consist of training) post-test was executed. It was used multivariate covariance analysis (MANCOVA) to analysis data by SPSS-22.
Sleep Quality Questionnaire

Pittsburgh sleeps quality index has designed by Buysse et al to measure sleep quality and help identify those who have a good or inadequate sleep. This self-report scale includes various fields such as perceived sleep quality, sleep latency (how long it takes to fall asleep), sleep duration, habitual sleep efficiency (how long a person is asleep in comparison to their time in bed), sleep disturbances, sleep medications and daytime dysfunction (sleepiness, concentration). Most items have been designed as several choices and are understandable easily. Responses range are $0-3$, and scores range consist of 0-21 (16). Validity and reliability of the Pittsburgh questionnaire are 0.86 and 0.89 respectively (17).

\section{Results}

The total number of the nurse in both groups was 40, 11 female and nine male in the experimental group, and 12 female and eight male in the control group. The mean and standard deviation of age in the experimental group was $37.33 \pm 12.21$ and in the control group was $35.38 \pm 11.81$. It was used multivariate covariance analysis to evaluate the research hypothesis (Table 1). In the MANCOVA model in the current study, the response variable is the measured subscales of sleep quality after the intervention, and the predictor variables are groups (which includes the control and intervention group) and subscales of sleep quality before the intervention. According to the findings of Table 1 , the variance is 0.95 and the values higher than 0.14 , show the high effect value. Also, the results of LambdaWilkes test on this combined variable were significant, which indicates that the participants in the 2 groups were different and the mean of the experimental group after the intervention was significantly improved compared to the control group.

Table 2 shows that the mean and standard deviation scores of the experimental and the control groups in the pre-test and post-test. As can be seen, the mean score of the experimental group in the post-test has a significant improvement in sleep quality and all its dimensions, but the mean scores of the control group in advance Test and post-test did not differ significantly.

Table 3 shows the adjusted means of the research variables. As can be seen, the mean of the experimental group is in a better position than the control group. Also, in the table, MANCOVA has been shown. According to seven dependent variables with the division of 0.05 to 7 , Bonferroni correction has implemented, so the significant limit is less than 0.007. According to ETA value, approximately $77 \%$ of variance of sleep quality,

Table 1. Multivariate Covariance Analysis and F Value for the Combined Variable, i.e. Sleep Quality

\begin{tabular}{llll}
\hline Interaction & $\mathbf{F}(7, \mathbf{2 5})$ & $\boldsymbol{P}$ value & ETA \\
\hline Group combined variable & 67.470 & 0.0001 & 0.950 \\
\hline
\end{tabular}


Table 2. Statistical Indicators of Dependent Variables for Experimental and Control Groups

\begin{tabular}{|c|c|c|c|c|c|c|c|c|}
\hline \multirow{3}{*}{ Variables } & \multicolumn{4}{|c|}{ Experimental Group } & \multicolumn{4}{|c|}{ Control Group } \\
\hline & \multicolumn{2}{|c|}{ Pre-test } & \multicolumn{2}{|c|}{ Post-test } & \multicolumn{2}{|l|}{ Pre-test } & \multicolumn{2}{|c|}{ Post-test } \\
\hline & Mean & SD & Mean & SD & Mean & SD & Mean & SD \\
\hline Sleep quality & 2.55 & 0.51 & 0.60 & 0.50 & 2.25 & 0.63 & 2.30 & 0.47 \\
\hline Sleep latency & 2.45 & 0.60 & 0.60 & 0.50 & 2.10 & 0.64 & 2.15 & 0.67 \\
\hline Sleep duration & 2.00 & 0.63 & 0.75 & 0.72 & 2.00 & 0.32 & 2.25 & 0.44 \\
\hline Habitual sleep efficiency & 2.35 & 0.58 & 0.10 & 0.30 & 2.15 & 0.58 & 2.00 & 0.56 \\
\hline Sleep disturbances & 2.00 & 0.56 & 0.75 & 0.44 & 1.95 & 0.68 & 1.76 & 0.71 \\
\hline Sleep medications & 2.05 & 0.68 & 0.30 & 0.87 & 2.35 & 0.67 & 2.30 & 0.73 \\
\hline Daytime dysfunction & 1.90 & 0.71 & 0.45 & 0.51 & 1.60 & 0.88 & 1.60 & 0.88 \\
\hline
\end{tabular}

Table 3. Statistical Indicators of Dependent Variables for Experimental and Control Groups (Adjusted)

\begin{tabular}{|c|c|c|c|c|c|c|c|}
\hline \multirow{3}{*}{ Variables } & \multirow{2}{*}{\multicolumn{2}{|c|}{$\begin{array}{l}\text { Experimental Group } \\
\text { Post-test }\end{array}$}} & \multirow{2}{*}{\multicolumn{2}{|c|}{$\begin{array}{l}\text { Control Group } \\
\text { Post-test }\end{array}$}} & \multicolumn{3}{|c|}{ Covariance Analysis } \\
\hline & & & & & \multirow{2}{*}{$F(1,31)$} & \multirow{2}{*}{ P-value } & \multirow{2}{*}{ ETA } \\
\hline & Mean & SD & Mean & SD & & & \\
\hline Sleep quality & 0.607 & 0.112 & 2.93 & 0.112 & 100.160 & 0.0001 & 0.764 \\
\hline Sleep latency & 0.503 & 0117 & 2.247 & 0.117 & 97.911 & 0.0001 & 0.760 \\
\hline Sleep duration & 0.748 & 0.129 & 2.252 & 0.129 & 59.725 & 0.0001 & 0.658 \\
\hline Habitual sleep efficiency & 0.118 & 0.116 & 1.982 & 0.116 & 112.542 & 0.0001 & 0.784 \\
\hline Sleep disturbances & 0.707 & 0.127 & 1.793 & 0.127 & 32.181 & 0.0001 & 0.509 \\
\hline Sleep medications & 0.412 & 0.126 & 2.188 & 0.126 & 86.873 & 0.0001 & 0.737 \\
\hline Daytime dysfunction & 0.333 & 0.156 & 1.717 & 0.156 & 34.370 & 0.0001 & 0.526 \\
\hline
\end{tabular}

$76 \%$ of sleep latency, $66 \%$ of sleep duration, $78 \%$ of variance of habitual sleep efficiency, $51 \%$ of variance of sleep disturbances, $74 \%$ variance of sleep medications and $53 \%$ of daytime dysfunction were influenced by the intervention in the experimental group is predictable.

\section{Discussion}

This study aimed to determine the effectiveness of progressive muscle relaxation on nurses' sleep quality since there has not been any research in this field in Iran. Therefore, in explaining the hypotheses, we have tried to point out the closest research to the present subject. The findings showed that there is a significant difference between experimental and control groups on sleep disorders, after PMR intervention, in the experimental group. This difference indicates that the efficacy of this instruction upon the experimental group. These results are consistent with Saeedi et al (15), Dehdari et al (18), Jalal Manesh and Zargarani 2015 (19), Zargarani (20), studies. In explaining the effectiveness of progressive muscle relaxation on sleep quality, according to the PSQI subscale, it can be said that this method has been effective on the overall description of sleep deprivation, because this is the most practical mechanism for dealing with overnervous activity through one's knowledge of controlling its own body (21). It breaks down the cycle by relaxing the muscles and reducing the nervous activity. The therapist can relieve tension from the muscles and calm her nervous system by detecting tension in the muscles of the body and face and releasing it from it (18). The sympathetic system of the nervous system stopped during the relaxation instruction. Moreover, the parasympathetic system becomes more active. In the peak state of arousal, the sympathetic system activates the nervous system of the fight or escape reaction, and the parasympathetic nervous system remains in a fragile state. After relaxation, when the person unleashes his nervous system from many stimuli, he can think better and distinguish affairs more efficiently and effectively. Nerves centers of the brain can exacerbate or weaken the autoimmune centers of the sympathetic and parasympathetic centers to some extent. Messages sent from some areas of the cortex and limbic system changes automatic sympathetic and parasympathetic responses and also blood pressure, heart rate, and digestion activity. The basis of biofeedback techniques is the use of the automated nervous system to affect the voluntary centers of the brain (15). Awareness of physical changes and biological processes of organs, tissues, and voluntary effort to restrain and restore them to the desired state are biological which helps the therapist to manage all aspects of his/her life better (22). According to sleep quality scales, we can better understand that the tensions generated by daily work rotation and the problems that nurses are involved in, makes it extremely difficult for their daily controlling ability. Adding to this the difficulty of falling asleep as part of their job, all of which will be a problem for them, but progressive muscle relaxation, as a kind of relaxation-learning and biofeedback technique, 
teaches them how to reduce the tension of their muscles (23). This method has been effective in lowering blood pressure in some people as much as antihypertensive drugs (14). Summarizing the studies in which biofeedback and relaxation are used to treat headaches and blood pressure, the most critical variable in these measures is the same learning method of relaxation. Some people learn relaxation quickly through the biofeedback, and some people without biofeedback learn how to release muscle as quickly as learning relaxation (24). Recently, there is sufficient evidence for the conclusion that the relaxation learning is a proven and effective treatment in the treatment of insomnia, for example, the effect of muscle relaxation on insomnia studied in nurses of the heart center of Tehran, and the results showed that after one month in the intervention group, the incidence of insomnia was significantly decreased (25). A study in Arak has also investigated the effect of muscle spasm on insomnia in hemodialysis patients, which indicated that relaxation therapy is effective upon these patients insomnia reducing (15).

\section{Conclusion}

In conclusion, considering that in our country $80 \%$ of health care workers are nurses who are in the first place in providing health services. Nurses usually operate irregularly in working shifts (morning, evening, night) and are more exposed to mental stress than other occupations and this causes them to become insomnia and irregular patterns of sleep that reduce sleep quality and sleep duration and finally reduce job performance. Therefore, it is necessary to reduce sleep problems and improve the sleep quality in this group with suitable programs. Since the effectiveness of the interventional method of PMR on the sleep quality in this study and other researches has proven, this method can consider as a suitable method for reducing sleep problems in nurses. Finally, it suggested that this method used as a complementary therapy recommended for people with sleep problems.

\section{Conflict of Interest Disclosures}

The authors declare that they have no conflict of interests.

\section{Ethical Statement}

The current research was approved by the local ethics committee of Islamic Azad University Tonekabon Branch.

\section{Acknowledgment}

This article is the result of a research project approved by the ViceChancellor for research and technology of Islamic Azad University Tonekabon Branch. Thanks to all the nurses at Imam Sajad Hospital in Ramsar, who involved extremely in this research.

\section{References}

1. Irwin MR, Olmstead R, Carroll JE. Sleep Disturbance, Sleep Duration, and Inflammation: A Systematic Review and Meta-Analysis of Cohort Studies and Experimental Sleep Deprivation. Biol Psychiatry. 2016;80(1):40-52. doi: 10.1016/j.biopsych.2015.05.014.
2. Salehi K, Alhani F, Sadeghniyat K, Mahmoudifar Y, Rouhi N. Quality of sleep and related factors among Imam Khomeini hospital staff nurses. Iran Journal of Nursing. 2010;23(63):1825.

3. Yazdi-Ravandi S, Taslimi Z, Haghparast A, Ghaleiha A. Quality of life in patients with chronic pain disorders: Determinnation the role of intensity and duration of pain. Koomesh. 2016;17(4):836-43.

4. Yazdi-Ravandi S, Taslimi Z, Saberi H, Shams J, Osanlo S, Nori G, et al. The Role of Resilience and Age on Quality of life in Patients with Pain Disorders. Basic Clin Neurosci. 2013;4(1):24-30.

5. Suzuki K, Ohida T, Kaneita Y, Yokoyama E, Miyake T, Harano $S$, et al. Mental health status, shift work, and occupational accidents among hospital nurses in Japan. J Occup Health. 2004;46(6):448-54.

6. Madide S. Effects of night shift schedules on nurses working in a private hospital in South Africa. Lulea, Sweden: Lulea University of Technology; 2003.

7. Razmpa EGM, Sadeghniiat Haghighi K, Ghelichnia $H$, Ghobaei M, Rezaei N, et al. Sleep disorders and it is risk factors in nurses. Occupational Medicine Quarterly Journal. 2009;1(1):20-3.

8. Sadock BJ, Sadock VA, Ruiz P. Kaplan and Sadock's synopsis of psychiatry: behavioral sciences/clinical psychiatry. 11th ed. Philadelphia: Lippincott Williams \& Wilkins; 2014.

9. Chien PL, Su HF, Hsieh PC, Siao RY, Ling PY, Jou HJ. Sleep Quality among Female Hospital Staff Nurses. Sleep Disord. 2013;2013:283490. doi: 10.1155/2013/283490.

10. Demiralp M, Oflaz F, Komurcu S. Effects of relaxation training on sleep quality and fatigue in patients with breast cancer undergoing adjuvant chemotherapy. J Clin Nurs. 2010;19(78):1073-83. doi: 10.1111/j.1365-2702.2009.03037.x.

11. Natarajan G, Sreehari R. Progressive Muscular Relaxation as a Multi-pronged psychotherapeutic technique for Insomnia. Amrita J Med. 2014;10(1):1-44.

12. Jones D, Owens M, Kumar M, Cook R, Weiss SM. The effect of relaxation interventions on cortisol levels in HIV-seropositive women. J Int Assoc Provid AIDS Care. 2014;13(4):318-23. doi: 10.1177/2325957413488186.

13. Blanaru M, Bloch B, Vadas L, Arnon Z, Ziv N, Kremer I, et al. The effects of music relaxation and muscle relaxation techniques on sleep quality and emotional measures among individuals with posttraumatic stress disorder. Ment IIIn. 2012;4(2):e13. doi: 10.4081/mi.2012.e13.

14. Bracke PE. Progressive Muscle Relaxation. In: Weiner IB, Craighead WE, eds. The Corsini Encyclopedia of Psychology. New Jersy: John Wiley \& Sons; 2010.

15. Saeedi M, Ashktorab T, Saatchi K, Zayeri F, Amir Ali Akbari S. The effect of progressive muscle relaxation on sleep quality of patients undergoing hemodialysis. Iran J Crit Care Nurs. 2012;5(1):23-8.

16. Buysse DJ, Reynolds CF, 3rd, Monk TH, Berman SR, Kupfer DJ. The Pittsburgh Sleep Quality Index: a new instrument for psychiatric practice and research. Psychiatry Res. 1989;28(2):193-213.

17. Shahri Far M. The effect of relaxation on quality of life and the rate of nurse'drowsiness while at work [Thesis]. Ahvaz: Jundishapur University of Medical Sciences; 2008.

18. Dehdari T, Heidarnia A, Ramezankhani A, Sadeghian S, Ghofranipour F. Effects of progressive muscular relaxation training on quality of life in anxious patients after coronary artery bypass graft surgery. Indian J Med Res. 2009;129(5):6038.

19. Jalalmanesh SH, Zargarani F. Effects of progressive muscle relaxation technique on fatigue and sleep quality in patients 
with multiple sclerosis. Sci J Hamadan Nurs Midwifery Fac. 2015;23(3):5-14

20. Zargarani F, Kamkar MZ, Maghsoudlou A. The effect of progressive muscle relaxation technique on the quality of sleep and fatigue in patients with multiple sclerosis. J Urmia Nurs Midwifery Fac. 2018;15(12):911-20.

21. McCallie MS, Blum CM, Hood CJ. Progressive muscle relaxation. J Hum Behav Soc Environ. 2006;13(3):51-66. doi: 10.1300/J137v13n03_04.

22. Lehrer PM, Gevirtz R. Heart rate variability biofeedback: how and why does it work? Front Psychol. 2014;5:756. doi: 10.3389/fpsyg.2014.00756.
23. Pangotra A, Singh TK, Sidana A. Effectiveness of Progressive Muscle Relaxation, Biofeedback and L-Theanine in Patients Suffering from Anxiety Disorder. Journal of Psychosocial Research. 2018;13(1):219-28.

24. Yucha CB, Tsai PS, Calderon KS, Tian L. Biofeedback-assisted relaxation training for essential hypertension: who is most likely to benefit? J Cardiovasc Nurs. 2005;20(3):198-205.

25. Pashang M, Manshaei GR, Sadeghniyat K, Ayatolahzadeh Esfehani $F$, Jalali A. The effect of muscle relaxation training on nurses' insomnia in Tehran Heart Center. J Cardiovasc Nurs. 2013;2(1):42-7. 